\title{
Development of Communicative Competencies During Integrated Analysis and Synthesis of a Text
}

\author{
Stepan Postil ${ }^{1}$, Nataliia Kozak ${ }^{2}$, Natalia Zykun 3 , Petro Tsymbal ${ }^{2} \&$ Hanna Vlasova $^{4}$ \\ ${ }^{1}$ Department of Intellectual Controlling and Computing Systems, University of the State Fiscal Service of Ukraine, Irpin, \\ Ukraine \\ ${ }^{2}$ Department of Criminal Procedure and Forensics, University of the State Fiscal Service of Ukraine, Irpin, Ukraine \\ ${ }^{3}$ Department of Journalism, Ukrainian Literature and Culture, University of the State Fiscal Service of Ukraine, Irpin, \\ Ukraine \\ ${ }^{4}$ Department of Public and Private Law, Borys Grinchenko Kyiv University, Kyiv, Ukraine
}

Correspondence: Stepan Postil, Department of Intellectual Controlling and Computing Systems, University of the State Fiscal Service of Ukraine, Irpin, 08201, Ukraine. E-mail: s-postil@nuos.pro

Received: September 14, 2021

Accepted: October 7, 2021

Online Published: October 21, 2021

doi:10.11114/smc.v9i2.5385

URL: https://doi.org/10.11114/smc.v9i2.5385

\begin{abstract}
Text is the main tool for designing and managing the learning and education processes. The communicative competencies of the individual are an important component of students' activities including working with documents, the ability to conduct interpersonal and social dialogue, and speak publicly. There is a theory that it is possible to develop a student's personal competence effectively through the integration of academic disciplines which in turn necessitates methods selected by the authors. The purpose of this study is to develop a project-based pedagogical technology that involves complex analytical and synthetic work with the text (CASWT) and contributes to the development of students' communicative competencies. In the course of this study methods of empirical and qualitative observation, analysis and synthesis were used. The practice of combining independent work with text and self-control using subject-specific thematic tests in the Moodle learning environment has been empirically researched. The content of the gained knowledge, faculties, skills, and activities of students after completing project tasks for working with text and communications, which ensure general and special (professional, subject) competencies of applicants for various specialties in compliance with the standards of higher education of Ukraine, is studied. The results of the study are developed graph-diagram which describes logical connections between the main text subjects, observation, analysis and evaluation of the results of work during several years, which allow increasing the quality of performance of the students and their psychological confidence, persuasiveness during studying other disciplines in next years of study.
\end{abstract}

Keywords: text, teaching methods and tools, mixed form of learning, Moodle learning environment, integrated analysis and synthesis of the text

\section{Introduction}

The personality-oriented professional training with its individualised forms will contribute to the transition from mass-reproductive to systemic-active and individual-creative models of training competent specialists. The task of the teacher is to involve the student in educational activities, organise the process of independent search for new knowledge, using the gained knowledge for solving cognitive, educational, practical, and mundane problems by using effective methods and means of teaching in various forms of learning (conventional learning, distance learning, mixed as a combination of conventional and distance learning).

A desirable result can be achieved if the necessary level of development of the educational environment is reached by using computer-oriented teaching tools. This will provide participants of the educational process with new forms of presentation of educational material, new means for the activity of students, which help to maintain a new level of communication and interaction between participants of the educational process (Kondratenko et al., 2009).

The development of communicative competencies is included in general personality development. The components of a specialist's competence usually include knowledge; willingness to acquire them (cognitive skills); faculties, practical 
skills; attitude (towards cognitive activity in particular); understanding, emotional intelligence; experience, a system of values and ethical attitudes; motivation of the individual. Working on the professional competence of specialists should be discussed, considering the principle of unity of consciousness and activity (Prokopenko et al., 2011). Professional awareness is interpreted as the theoretical preparedness of a specialist for professional activity and the practical preparedness of a specialist to perform professional duties.

Besides abilities and personal traits, various skills are necessary to solve mundane problems, which are developed during studying a particular discipline based on its content. However, a person rarely faces tasks that are limited to those of academic discipline in one's everyday life. Often, mundane challenges require advanced disciplinary skills. Therefore, it is important to develop them by combining the capabilities of several separate disciplines, consistently developing each group of skills such as organisational, intellectual, evaluative, communicative ones.

The desirable result of the training of competent specialists can be achieved by using interdisciplinary connections and integrating various disciplines focused on the development of general academic skills (Mykytenko \& Lapinsky, 2020; Postil \& Kozak, 2017). According to M. Pentyluk, the connection between all academic disciplines is a text as a means of developing a system of values, communicative, speech, and socio-cultural competence of the student (Mykytenko \& Lapinsky, 2020). The results of modern research indicate the importance of competent work with texts for student employment opportunities (Salama \& Oláh, 2019), ensuring the effective operation of enterprises (Bashynska, 2012; Žul'ová et al., 2018) and the entire industries (Žul'ová et al., 2018; Prokopenko \& Miśkiewicz, 2020).

For the mixed form of learning, the distance component of the course plays an important role, which is presented not only as texts for the lessons, information and communication technologies, and teaching tools but as an integral process that involves the understanding of the material and active exchange of information and opinions with the teacher and the students. The poor quality of text or other information or lack of thereof in the distance component of the course equals to the absence of a distance component in the educational process. In addition, the distance learning component is the comprehension of knowledge through personal activities and cooperation at the same time. Thus, the text should be focused on variables (by performance styles) and adapted to the activity of the set goal. These factors are prerequisites and new opportunities for the principle of individual student learning approach with the choice of educational goal, forms, means, and pace of learning.

Important features of the text are dialogic, meaningfulness, coherence, integrity, completeness, structure, divisibility, informativeness (Khairova et al., 2019). For the organisation of working with text, it is important to understand the features and possibilities of the main types of reading such as viewing, introductory, and "studying" ones, which help to understand the text on different levels (Zakaria \& Buang, 2012). Understanding is a process that has dynamic and meaningful features, causes occurrence, strategies, and means of implementation, stages of functioning (Akimova $\&$ Oleksandrenko, 2019). In addition, understanding is a reflection of the inner values, goals of the subject, one's spiritual activity, and life context in the first place. Thus, understanding is an indicator of both personal and spiritual development (Romanovska, 2005).

Understanding the text, which is a complex organised semantic entity, is deepened by repeatedly rereading it from different perspectives. The reader as an active subject of understanding can make additions to the text. It depends on their knowledge and attitudes, on their goals and motivations for reading. Understanding implies that information is both expanded and minimised due to a number of cognitive operations by structuring and re-structuring the text, in particular, minimising and unfolding the meaning of the message. The purpose of this structuring is to establish logical connections between separate text fragments. Even a mature reader's understanding of the text does not always reconstruct the exact meaning of the text that is implied by the author.

N. Ihnatenko identifies four stages of readers' understanding of the text (Ignatenko, 2001):

1) understanding of the actual content of educational material (readers' understanding and reproduction of the actual content of what they read);

2) semantic analysis of the text (understanding the main features, essential connections, relationships, etc.);

3) structural analysis of the text (structuring the text into logical parts; defining its components in the text);

4) dialogue between the reader and the text, generalisation of what has been read (deepening the understanding of the text, identifying the reader's personal attitude to the content of what has been read).

Considering the analysis of psychological and didactic research, the list of techniques that contribute to the understanding of educational texts can be summarised:

1) verbal preparation of a text plan (its structural and logical analysis);

2) correlation of the text content with the reader's questions, incorporation of messages contained in the text into the 
structure of one's knowledge;

3) correlation of different parts of the text such as the one that is currently being read with those that have already been read, but not according to its structure but to its content;

4) using visual representations, images; transformation of the content of the text with one's perception;

5) reader's questions that are ahead of the presentation;

6) anticipation as the advancement, guessing the content of the next part of the text (Ignatenko, 2001).

Understanding the text is an indirect analytical-synthetic process aimed at achieving a certain result of cognitive activity, which involves a system of cognitive and dialogical interaction of the student with the text, which is evidence of high reading competence.

Academic, legal, artistic, political, economic, and media texts can be distinguished by their field of use. For example, legal documents such as business papers as judicial evidence can be classified into the groups by source of origin, by content, by purpose, by method of verifying events, and by form. Depending on specialists' experience of working with documents, it will later be determined whether they become material evidence or not (Friedman \& Tsymbal, 2003). Media texts differ from other types of texts by using, systematising and reducing, processing and formalising all other types of texts that are considered $t$ be "primary" in a certain way. As a result, a new type of text appears, including its rules of construction and design of content.

One of the most relevant types of texts for students is academic one. The academic text is known for a large number of terms and concepts that have an abstract meaning. The latter requires sufficient development of abstract thinking among students, as well as well-developed thought processes, analysis and synthesis. Confirmation of the comprehension of an academic text is its understanding, that is, the definition of the essence of objects and phenomena described in the text, awareness of connections, relationships and dependencies between them. Scientific knowledge requires its intellectual perception (perception of content, understanding of concepts and terms) unlike the perception of works of fiction, where the emotional aspect plays a leading role. Artistic perception is united with intellectual one, and intellectual perception, in its turn, occurs during a certain emotional experience, which determines the nature of perception.

An important component a specialist's activity (and the individual in general) is the communicative competencies of a person, which belong to the basic professional features. They contain three main components: 1) working with documents (analysis, creation, structuring and restructuring, folding and unfolding); 2) having an interpersonal and social dialogue; 3) public speaking (Shevchuk \& Klimenko, 2011).

The "language standard for professional activity" is a number of competencies developed in the process of educational and linguistic activities, ensuring preparedness for professional effectiveness and success. It combines:

1) development of a thesaurus of the profession, enrichment of vocabulary, understanding of terminology (emphasising on the main lexical phenomena and processes in its structure: synonymous, paronymic, antonymic; considering the variability of context, the influence of international lexical units; professional phraseology, etc);

2) preparation for linguistic presentation of the progress and results of activities in documents and media reports, ensuring document flow and information exchange;

3) adoption of the principles and regularities of verbal professional communication for the representatives of a certain profession (Goian et al., 2020).

Public speaking is the subject of a study of rhetoric, which is the theory of public speaking and the science of eloquence, which professor of the Kyiv Mohyla Academy F. Prokopovych considered to be "the queen of souls", "the queen of arts", emphasising its social and organisational (a means of "agitation"), cultural and educational functions, as well as gaining knowledge, evoking feelings, shaping public opinion, etc. (Shevchuk \& Klimenko, 2011; Sagach, 2000).

A number of features that represent the professional portrait of a specialist can be identified (Shevchuk \& Klimenko, 2011), including setting goals and objectives of professional communication; the analysing the subject of communication, organising discussions; managing communication, regulating it; using etiquette norms to achieve a communicative goal; the willingness to participate in a conversation, interview, discussion, dialogue, debate, negotiations; using various tactics for the chosen strategy; analysing conflicts, critical situations and solving them; proving, justifying, motivating, arguing, refusing, denying, rejecting, evaluating; paraphrasing, developing a thesis, possessing verbalisation skills; transforming verbal information into written and vice versa; being knowledgable about the main types of business communication (official letters, fax messages, contract, telephone conversation, business conversation, negotiations, meeting, etc.); being perfectly literate, adhering to both written and oral-literary language norms; mastering communication techniques; using rhetorical techniques adequately; correcting behaviour of the interlocutor through verbal means. 
The purpose of the article is to study the content specifics and features of communicative competencies of the individual; the choice of methods and means of their development in a mixed form of learning during integrated analysis and synthesis of the text. The task of the study is to accumulate, interpret and discuss the data obtained in this research, draw conclusions.

\section{Materials and Methods}

The need for new approaches to learning with a limited number of classroom sessions remains an issue for most educational communities. The solution to these issues is impossible without the large-scale implementation of online technologies, fundamental changes in approaches to the organisation of learning in educational institutions and every discipline, changes in the role of auditorial classes, and their effectiveness in particular (Recommendations for the introduction of blended..., 2020).

Mixed forms of learning are one of the most popular technologies now, as they allow for benefiting from the flexibility and convenience of the distance component of the course and the advantages of conventional classroom learning. The didactic goal of learning in terms of the essence of understanding the content of material with the implementation of online technologies remains the same. However, its structure, methods, teaching tools, and the form of its organisation in the system of interaction "student-teacher", "student-student" and "student-computer" has transformed (Kukharenko et al., 2016).

There is a need for structuring the course content, student activities, homework assignments, and lectures. When planning activities, it is necessary to transform the usual classes into interactive learning of subjects, which can be done synchronously (when everyone is online at the same time as in web seminar, video conference, etc.) and asynchronously (when each participant performs activities at different times as in chat, forum, etc.), as well as into organised independent work of the student (Recommendations for the introduction of blended..., 2020).

Active methods are the leading ones among the methods of distance learning. In particular, the most successful is learning in cooperation (to activate the cognitive activity of each student in networks), project methods, including research and problem-based ones (for creative integrated application of the gained knowledge based on individual tasks and end-to-end research objects (Postil \& Kozak, 2017).

These methods are based on independent work of students, which is done at an individual pace and under the supervision of the teacher, or under the control of special software tools sometimes, and focused on the active participation of the student in the search for knowledge, development of proficiencies and skills, the discovery of one's creative potential.

Tools for a mixed form of learning are used to manage educational and cognitive activities and display the content of educational material visually. The means of learning are text materials (methodological, informational, routine, etc.) and information and communication technologies such as a personal computer; internet; corporate network of the university; interactive whiteboard with electronic pencils; multimedia projector; distance learning platforms; specialised software (for example, Viber application, BigBlueButton for holding a web conference, etc.) (Kukharenko et al., 2016).

The distance learning platform includes the LMS (Learning Management System). Along with commercial solutions, there are open-source platforms on the market (for example, Moodle, Sakai, Litmos, Claroline, DotLRN, BrainCert, Open edX, Canvas, etc.). At the same time, the integrated use of learning tools contributes to the development of interactive teaching methods.

At this stage, there is no universal mixed learning model. Basic approaches to the implementation of any mixed learning model are important, and the features of each discipline, the personal traits of students, and individual pedagogical approaches of the teacher create prerequisites for the development of their effective models (Recommendations for the introduction of blended..., 2020). Since external communication (with the tutor and colleagues) is not constant in the distance component of the course and follow every stage of the student's cognitive activity, it is necessary to provide for an internal dialogue of the student with the text. This can be done in the following ways:

- $\quad$ by submitting information not as a given fact but in the form of a discussion;

- including rhetorical and other questions in the narrative text, immediate offer of their analysis and possible answers can be proposed if necessary;

- $\quad$ structuring the text into separate units with alternative approaches and perspectives about the material presented;

- interspersing linear text with other means of transmitting information such as schemes, tables, diagrams, drawings, statements of famous figures, and so on. It is preferable to give an explanation along with the visual aids that does not repeat what was said earlier in the text in the same way;

- $\quad$ providing open questions designed for students' reflection and including an initial example of finding an answer to 
such a question;

- constantly providing thesaurus for the educational text, which can be placed side by side in the margins;

- analyse possible variable or paradoxical situations, show the ideological significance of the information presented, its humanistic, cultural, and social role if it exists in the objective reality.

Awareness regarding the learning processes is the most important value of learning in education, regardless of the forms of learning. This will encourage higher education applicants to be more independent and self-regulatory in their studies. Thus, a modern specialist is a highly qualified professional who combines general erudition with knowledge in a specific field of activity, can identify strategic issues, establish mutual understanding and interaction with the public, a specific social group, individuals, that is, adheres to the culture of communication in both direct or remote communication.

The study theoretical publications related to the research problem were analysed to reveal the main definitions, generalise the best methodological experience dedicated to the effectiveness of various approaches, innovative methods, and tools in a mixed form of learning.

136 respondents participated in empirical studies about students' self-learning using disciplinary tests and the Moodle personalised learning environment platform (36 of them - during the study of 4 disciplines; 48 - during the study of 3 disciplines, 52 - during the study of 2 disciplines). Quantitative analysis of student test results was performed using Moodle tools followed by mathematical processing.

Independent work with the text is a holistic activity that reflects the willingness to use certain skills and ensures their development. Students' understanding of an academic text has a number of features and can cause difficulties, and, therefore, teachers should bring the student closer to the understanding of its content. The most productive is "educational" reading, which allows for comprehending the content of the text at the level of understanding and then solves practical problems of various levels of complexity.

For mastering "educational" reading, it is necessary to understand its main techniques: 1) defining keywords (terms); 2) clarifying the topic of the text; 3 ) identifying the problem of the text; 4) determining the main idea and arguments of the author. The student can check the level of understanding of the text by using the test, choosing the necessary type of reading independently. The implementation of this technology requires working with text independently by using the Moodle learning environment platform.

Conventionally, pre-developed tests for each discipline on individual topics are used to check the level of theoretical and practical preparedness of the student for seminars, performing laboratory (practical) work, as well as developing tests for the final control and exam based on them. The developed tests can also be used for self-assessment of the level of understanding of theoretical material by the student.

For this purpose, the following Moodle parameters were provided during testing: 1) the mode for setting access to a separate test is "long" (several days, weeks); 2) the mode for setting access to a separate test task is "long" (30-45 minutes); 3) a number of attempts are "several" (for example, 3); 4) a number of correct answers are a) at the end of every test; b) at the end of all tests. At the same time, the student must achieve a result of at least 60 percent of the correct answers. The analysis of independent work with text with this technology allowed for assessing not only the level of training of the student but also personal indicators of one's development.

When selecting the parameter "at the end of every test task" in the "number of correct answers" option, the vast majority of students achieved maximum results after the third attempt. Students recorded the correct answers to the test task and focused on the rest of the tasks. When selecting the parameter "upon completion of the whole test" in the "number of correct answers" option, the level of self-learning of students was in the range from 40 to 90 percent.

Thus, the technology of independent work with text using thematic tests with activation of the parameter for viewing testing "upon completion of the whole test" is more promising and effective for an individual creative model of student learning.

\section{Results and Discussion}

One of the tasks of higher education is to develop the modern educational scenario for the development of students' communicative competencies considering the laws of humanisation, humanitarisation, and democratisation. The development and establishment of students' communicative competencies will have a positive impact on the professional level of future specialists, their creative self-realisation, improvement in their activities, which is necessary for future specialists for adequate orientation in all public spheres (Kravchenko-Dzondza, 2016).

In the conditions of various forms of learning with the use of computer-oriented teaching aids, the authors of the study have developed and implemented project pedagogical technology in the process of performing complex analytical and 
synthetic work with the text (CASWT). This is a pedagogical activity for an academic educational process, considering information and communication technologies and human resources and their interaction for the development of communicative competencies of the student. Individual research topics of this work are developed considering the general and special (professional, subject) competencies of students. The CASWT technology implies six interrelated projects. In each of these projects, several tasks were presented to the students, in completion of which they could obtain skills, faculties, and knowledge for the development of communicative competencies.

In the first project, students were presented with the task of "Creating a text based on the specific research topic". To complete a set task, they had to find the necessary information in various relevant sources (paper documents, electronic manuals, academic articles, educational materials from the university repository, distance courses in the Moodle system, the Internet, etc.); be aware of information and communication technologies for receiving, processing and transmitting information; extract the necessary data from the information, systematising it according to certain criteria, and emphasising the main idea in the message; establish connections between different messages; finding errors and distortions in the text; comprehend and understand the perspectives different from the source; create personal reasonable statements about the message; develop a justification of the relevance of the research topic and its prospects; organise the prepared text according to the requirements. This project aims to confirm the prepared text (analysis and acceptance of the teacher's comments, considering appropriate edits).

In the second project, students were presented with the task of "Development of non-standardised tests based on the generated text". To complete the set task, they had to structure the completed text into content blocks; systematise them according to certain features, and select the main data. This project aims to generate 5-6 probable answers to the test question for the development of prospects for an individual creative model for student training.

In the third project, students were presented with the task of "Creating an abstract based on the generated text and tests". To complete a set task, they had to understand the purpose, structure, and requirements for creating an "abstract" that briefly presents the main thesis of the study; analyse the completed text and tests, and create personal reasonable statements, considering the scientific and professional context of the topic; state the basic thesis of one's reviewed text (regarding its topic, problem, subject, methods used by the author, results obtained, practical significance, etc.); develop the description of the text in accordance with the requirements for an "abstract" (logic, accuracy, avoiding ambiguity, clarity, etc.); use the tools of the appropriate functional style of speech (academic) (terms, professionalism, academic clichés, standardised figures of speech that convey the logic of the author's reasoning at different stages of working on the text). This project aims to develop a formal objective for self-assessment of one's project.

In the fourth project, students were presented with the task of "Preparing a review of the completed text, tests and abstract". To complete a set task, they had to understand the purpose, structure, and requirements for creating a "review"; analyse the completed text, tests, and abstract of another student and personal reasonable statements; perform critical reasoned analysis (analysis) of the thesis of texts prepared by colleagues; develop reasonable assessments of texts prepared by colleagues based on a critical analysis of the basic thesis of peer-reviewed materials (text, tests, and abstract); formally descript the text in accordance with the requirements for a "review"; performing a formal unbiased objective assessment of a project created by another specialist; illustrate generalised statements with extracts from peer-reviewed materials. This project aims to academically discussion in the review format.

In the fifth project, students were presented with the task of "Creating a multimedia presentation and report based on the text". To complete a set task, they had to understand the purpose, structure, and requirements for creating a "report" (content, formatting, etc.); work with dictionaries and reference books for messages; think through the ways and means of presenting information; create a report; understand the purpose, structure, and requirements for creating a "multimedia presentation" (content, formatting, multimedia effects, etc.); master the technology of analysis, formal description and visual representation of text; determine the form of visual presentation of information that is adequate to its content; translate one type of information into another (text to visual) and vice versa. This project aims to analyse the formal description and visual presentation of the text during optimising this type of project into a multimedia presentation.

In the sixth project, students were presented with the task of "Discussion of reports at an active training round table" (web conference). To complete a set task, they had to translate one type of information into another (verbal into visual) and vice versa; create an image by combining different types of information (verbal, text, and visual); determine the form of visual presentation of information that is adequate to its content; accurately and understandable explain one's thought process; actively develop speaking skills; improve the communication culture in general; transform information based on the features of the audience to which it is intended; understand the direction of information flow and communication goals; monologue speeches; develop socio-cultural and professional competence. This project aims to change students' attitudes towards information and communication technologies and teaching tools as changing factors 
of the educational process and timely professional activity and its functions (the computer is a source of information and is one of the means of presenting material).

After the completeness of all six projects, a round table (web conference) is held. This event has a certain scenario. Participants become familiar with the rules of conducting an academic round table (web conference). Then students report about work that they have done, with visual presentation, after which receiving questions from the listeners and give answers. Students reading out a review of the work and speaker response to the comments made in the review, then listeners and participants discuss the report. The teacher summarises the content and discussion of the student's report, after which evaluation of the students' materials, independent work, and their participation in the round table are commenced. The teacher gives recommendations on the prospects for the development of separate research topics, presentation of the report, academic and professional publications.

There is a generalised list of necessary communications to ensure general and special competencies of the students of "Information Technologies" (Order of the Ministry of Education..., 2019), "Law" (Order of the Ministry of Education..., 2018), "Journalism" degrees. Each of these skills was utilized in the above-mentioned projects.

In the first project, social communications were implemented in the process of communication with specialists and non-specialists in the field of computer science, ensuring the exchange of logical arguments to achieve mutual understanding and agreement. Sociableness, emotional stability, endurance, tact, skills were used during defending one's point of view, clear expression of one's opinion. Students used lexical and syntactic models common for professional communication, building communications in verbal and written form in the state and foreign languages based on the goals and situation of communication (Order of the Ministry of Education..., 2019; Order of the Ministry of Education..., 2018). They used communicative competence for effective interaction in various spheres of communication; selection and systematisation of information for communicating in the professional field, the using mass communication media to obtain, process, and create up-to-date information in the form of documents, essays, reports, articles, interviews; improvement of personal communication competence based on interpersonal communication skills (Order of the Ministry of Education..., 2019).

In the second project, students use document and information communication systems to meet information needs in the field of computer science, use professional and communicative contacts, understanding interlocutors, have psychological influence during communication, an adequate understanding of verbal and non-verbal communication signals, overcoming communication barriers. Plan communication with the team and with customers, following correct behavior, tolerance, order, recognition of other people's opinions and polite discussion, overcoming selfish views, principles of self-criticism, spreading the information about the working progress. Learn teamwork, perform business negotiations to transmit information using situation analysis, argumentation, and counterargument (Order of the Ministry of Education..., 2019).

In the third project, students develop communication plans for the project; preparation and management of meetings: identifying problems and diagnosing conflicts during working process. They plan and use interpersonal communications based on moral principles.

In the fourth project, students solve the problems of communities at various levels through volunteer activities involving participants in the educational process activities, joint management, and practical solution to team issues (Order of the Ministry of Education..., 2019).

In the fifth project, students develop effective communication strategies (through the accuracy of argumentation) in professional activities. They organise and control team professional activities. Learn how to promote the created product effectively (Order of the Ministry of Education..., 2019; Order of the Ministry of Education..., 2018).

In the sixth project, students justify one's opinion about the application of research methods in the field of professional activity during communicating with colleagues, clients, partners, making analytical reports, written reports, and presenting the results of their work at meetings, conferences, etc. (Order of the Ministry of Education..., 2019). They communicate conclusions clearly and unambiguously, as well as knowledge and explanations, ideas, problems, solutions that justify them, and their experience to specialists and non-specialists in the field of professional activity (Order of the Ministry of Education..., 2018).

The results of completing the tasks of the CASWT are obtained by students in accordance with the requirements in the form of relevant documents and stored on a web resource for sharing among this group. Considering the specificities of performing and completing complex analytical and synthetic work with the text, the following should be noted:

1) students have different theoretical (practical) training and different psychological, intellectual and educational levels;

2) separate research topics of this work are developed considering the general and special (professional, subject) competencies of students; 
3) separate research topics and an active, training form of an academic round table (web conference) are the foundation for motivating students to work on themselves, develop independence, decision-making skill, interaction, etc.;

4) an educational (training) round table (web conference) differs from other types of discussion of certain issues (academic conferences, etc.) in terms of the content of the scenario and tasks;

5) there is a differentiation of the roles of participants in the round table: students-speakers, students-listeners, students-reviewers, teacher-moderator, teacher-analyst, invitees.

Observation, analysis, and evaluation of the results of work during several years allow for ensuring the increase in quality of its performance by students and their psychological confidence, persuasiveness during studying other disciplines in the next years of study. Thus, the developed and implemented project pedagogical technology, which is based on CASWT, including for mixed forms of learning, contributed to the development of students' communicative competencies. Therefore, they provided improvement of communication proficiencies and skills in the educational and scientific, social and mundane, socio-cultural, official, and business spheres; mastering the forms of speech communication in various types of activities; development of faculties and skills to work with educational academic text, other sources of information; improvement of their skills of interpreting information.

\section{Conclusion}

The analysis of psychological and pedagogical research shows that the level of success in a mixed form of learning depends on the means and forms of organising pedagogical interaction between the teacher and the student and on the communicative competencies of each of them at the same time. The development of such competencies among students as the ability to think critically and creatively, analyse problems and generate solutions, communicate effectively and build relationships, prevent and constructively resolve conflicts, control themselves and manage stress is crucial in the modern situation. Text as a source of information, information and communication technologies, and teaching tools are not only tools for the development of communicative competence in completing educational tasks but also create conditions for independent research of students, encouraging them to develop orientation skills and independent decision-making.

A project-based pedagogical technology that involves CASWT and contributes to the development of students' communicative competencies has been developed and implemented in various forms of training using computer-oriented teaching tools. The study of the content of the gained knowledge, proficiencies, skills, and activities of students after completing the tasks of the CASWT and communications, which ensure general and special competencies of specialists of various specialties (122 "Computer Science", 081 "Law", 061 "Journalism") according to the standards of Ukrainian higher education. The results of studies of the influence of the mentioned types of work with text on the development of communication indicators of applicants showed the effectiveness of developed methodology contributed to the development of students' communicative competencies.

In the future, it is planned to study the evaluation of the impact of certain types of work with text on the development of communication indicators to ensure the professional activity of specialists, depending on different types of text in the fields such as scientific, legal, artistic, media, etc.

\section{References}

Akimova, N., \& Oleksandrenko, K. (2019). Impact of the internet using experience on the peculiarities of the internet texts understanding. Psycholinguistics, 26(1), 11-36. https://doi.org/10.31470/2309-1797-2019-26-1-11-36

Bashynska, I. (2012). Models of integrated marketing communications forming for innovatively active machine engineering enterprises. Economic Annals-XXI, 11/12, 52-54.

Friedman, I. Y., \& Tsymbal, P. V. (2003). Features of analysis and research of documents in the investigation of crimes in the field of taxation. Scientific Bulletin: Collection of Scientific Works of the Academy of the State Tax Service of Ukraine, 1(19), 108-116.

Goian, O., Goian, V., Biletska, T., Bessarab, A., \& Zykun, N. (2020). Communicative strategies of professional development of a TV and radio journalist: Psychotypology and social model. Academic Journal of Interdisciplinary Studies, 9(5), 147-157. https://doi.org/10.36941/ajis-2020-0093

Ignatenko, N. V. (2001). Didactic support of understanding of educational texts by pupils of initial classes: abstract of dissertation for the degree of candidate of Pedagogy. Kyiv: Institute of Pedagogy of the Academy of Pedagogical Sciences of Ukraine.

Khairova, N., Kolesnyk, A., Mamyrbayev, O., \& Mukhsina, K. (2019). The influence of various text characteristics on the readability and content informativeness. Proceedings of the 21st International Conference on Enterprise Information Systems, 1, 450-457. https://doi.org/10.5220/0007755004620469 
Kondratenko, N. Yu., Marchenko, H. V., \& Stezhko, S. O. (2021). Psychological and pedagogical principles of development of communicative competence of future journalists based on linguoculturology. Scientific Bulletin of Mukachevo State University. Series "Pedagogy and Psychology", 7(1), 113-120. https://doi.org/10.52534/msu-pp.7(1).2021.113-120

Korauš, A., Kaščáková, Z., \& Felcan, M. (2020). The impact of ability-enhancing HRM practices on perceived individual performance in the IT industry in Slovakia. Central European Journal of Labor Law and Personnel Management, 3(1), 33-45. https://doi.org/10.33382/cejllpm.2020.04.03

Kravchenko-Dzondza, O. (2016). Pedagogical conditions of formation of communicative competence of students. Scientific Bulletin of the Nikolaev National University named after V.O. Sukhomlinsky. Series: Pedagogical Sciences, 1, 98-103.

Kukharenko, V. M., Berezenska, S. M., Bugaychuk, K. L., Olyynik, N. Y., Olyynik, T. O., Ribalko, O. V., ... Stolyarevska, A. L. (2016). Theory and practice of blended learning. Kharkiv: Miskdruk.

Mykytenko, P. V., \& Lapinsky, V. V. (2020). Design of interdisciplinary integration of medical informatics. Information Technologies and Teaching Aids, 75(1), 26-41.

Order of the Ministry of Education and Science of Ukraine No. 1379 "Standard of higher education of Ukraine: the first (bachelor's) level of higher education, branch of knowledge 08 "Rights"'. (2018). https://mon.gov.ua/storage/app/media/vishcha-osvita/zatverdzeni\%20standarty/2019/07/12/122-kompyuterni-nauki -bakalavr.pdf [Accessed: 15/09/2021]

Order of the Ministry of Education and Science of Ukraine No. 962 "Standard of higher education of Ukraine of the first (bachelor's) level of the degree "bachelor" in the field of knowledge 12 "Information technologies" specialty 122

"Computer sciences"”. https://mon.gov.ua/storage/app/media/vishcha-osvita/zatverdzeni\%20standarty/2019/07/12/122-kompyuterni-nauki -bakalavr.pdf [Accessed: 15/09/2021]

Postil, S. D., \& Kozak, N. S. (2017). Integrativity of the system approach in educational process. Physical and Mathematical Education: Scientific Journal, 1(11), 84-88.

Prokopenko, O. V., Karminsky, A. M., \& Klymenko, O. V. (2011). The role of ratings in the educational process of higher education institutions. Marketing and Management of Innovations, 4(2), 141-146.

Prokopenko, O., \& Miśkiewicz, R. (2020). Perception of "Green Shipping" in the contemporary conditions. Entrepreneurship and Sustainability Issues, 8(2), 269-284. https://doi.org/10.9770/jesi.2020.8.2(16)

Recommendations for the introduction of blended learning in institutions of professional higher and higher education. (2020).

https://mon.gov.ua/storage/app/media/vishcha-osvita/2020/zmyshene\%20navchanny/zmishanenavchannia-booklets preads-2.pdf [Accessed: 15/09/2021]

Romanovska, L. I. (2005). Cognitive style of personality as a factor in the process of text comprehension: abstract of dissertation for the degree of candidate of. Psychology. Kyiv: G.S. Kostyuk Institute of Psychology of the National Academy of Pedagogical Sciences (NAPS) of Ukraine.

Sagach, G. M. (2000). Rhetoric. Kyiv, In: Publishing House "Yure".

Salama, A., \& Oláh, J. (2019). Key factors affecting unemployment in the Arab world. Central European Journal of Labor Law and Personnel Management, 2(2), 60-72.

Shevchuk, S. V., \& Klimenko, I. V. (2011). Ukrainian language for professional purposes. Kyiv: Alerta.

Zakaria, W. N., \& Buang, N. A. (2012). Analysis of text structure in the skills of reading economics text. GEMA Online Journal of Language Studies, 12(1), 295-309.

Žulová, J., Švec, M., \& Madleňák, A. (2018). Personality aspects of the employee and their exploration from the GDPR perspective. Central European Journal of Labor Law and Personnel Management, 1(1), 68-77.

\section{Copyrights}

Copyright for this article is retained by the author(s), with first publication rights granted to the journal.

This is an open-access article distributed under the terms and conditions of the Creative Commons Attribution license which permits unrestricted use, distribution, and reproduction in any medium, provided the original work is properly cited. 